\title{
WIC Recipients in the Retail Environment: A Qualitative Study Assessing Customer Experience and Satisfaction
}

\author{
Christina Chauvenet, MSc, MSPH; Molly De Marco, PhD, MPH; Carolyn Barnes, PhD; Alice S. Ammerman, DrPH
}

\author{
ARTICLE INFORMATION \\ Article history: \\ Submitted 4 January 2018 \\ Accepted 4 September 2018 \\ Available online 27 November 2018 \\ Keywords: \\ Grocery shopping \\ WIC \\ Retail environment \\ Benefits \\ Shopping experience \\ Supplementary materials: \\ Figure 1 is available at www.jandonline.org. \\ 2212-2672 \\ https://doi.org/10.1016/j.jand.2018.09.003
}

\begin{abstract}
Background The Special Supplemental Nutrition Program for Women, Infants, and Children (WIC) program is an important intervention for prevention and treatment of obesity and food insecurity, but participation has dropped among eligible populations from 2009 to 2015. Program satisfaction is integral to participant retention, and the retail experience is a vital component of program satisfaction.

Objective This article applies behavioral economics principles to explore the retail experience of WIC participants and ways in which it may be improved.

Design The authors designed and conducted semistructured interviews and focus groups with WIC participants.

Participants/setting A convenience sample of WIC participants aged 18 years and older were recruited through WIC clinics in Texas, North Carolina, Oregon, and Illinois $(\mathrm{n}=55,27$ participants from four focus groups and 28 individual interviews).

Statistical analysis conducted Responses were analyzed qualitatively using principles of content analysis.

Results Challenges in identifying WIC-allowable items throughout the store as well as perceived stigmatization during the checkout process were the chief complaints. Study participants described a learning curve in successful use of WIC in retail environments over time. Study participants also reported acceptance of restrictions, such as a requirement to purchase the least expensive brand.

Conclusions Dissatisfaction with the retail experience may lead to the underutilization of WIC benefits or program exit. Behavioral economics strategies that facilitate a better shopping experience, such as creating a section for WIC items in the store or improving in-store education, may improve the retail experience for WIC customers. Further research is needed to ensure such strategies are effective and do not contribute to stigma.

J Acad Nutr Diet. 2019;119(3):416-424.
\end{abstract}

$\mathrm{T}$ HE SPECIAL SUPPLEMENTAL NUTRITION PROGRAM for Women, Infants, and Children (WIC) has been critical in promoting maternal and child health and development and combating food insecurity since its inception in 1975. WIC provides supplemental foods, health care referrals, nutrition education, and breastfeeding support for low-income, nutritionally at-risk pregnant and postpartum women, infants, and children up to age 5 . As rates of childhood obesity among 2- to 5-year-olds increased from $5 \%$ in $1976-1980$ to $13.9 \%$ in $2015-2016,{ }^{1,2}$ and rates of obesity among women aged 20 to 39 increased from $20.7 \%$ in $1988-$ 1994 to $36.5 \%$ in $2015-2016,{ }^{1,3}$ obesity prevention has become a WIC program priority in addition to the provision of vital nutrients during early developmental stages. WIC participants are restricted to specific quantities and varieties within food categories (eg, 36 ounces of whole grain breakfast cereal), and food packages are consistent with scientific evidence on maternal and child nutrition. Additional changes to the WIC package in 2009 further enhanced the healthfulness of the food package by including, for example, whole grains and adding Cash Value Vouchers (CVVs) for the purchase of fruits and vegetables. ${ }^{4}$ Recent studies have found high acceptance for these changes and improved dietary intake among WIC recipients since changes to the WIC package were implemented. ${ }^{4-8}$

Despite the health and nutritional benefits of the WIC program, participation in the WIC program has declined since 2009. From 2009 to 2015 (the most recent year for which participation rates are available), WIC participation decreased from $62.9 \%$ of eligible recipients participating to $52.7 \%$ of eligible recipients participating (a decline in absolute number of participants from 9.18 million recipients to 7.93 million participants). $)^{1,5}$ Studies also suggest that some participants underutilize WIC benefits. In a sample of five states, from 2013-2016, product category redemption ranged from 31\% (infant meats) to $94 \%$ (infant formula). Of the items new to 
the 2009 WIC package, the fruit and vegetable voucher had a $77 \%$ redemption rate in this period, and whole-grain bread had a 53\% redemption rate. ${ }^{6(\mathrm{p} .92)}$ The retail environment plays a critical role in utilization of WIC, because WIC benefits must be purchased at stores (or in some states at farmers' markets). ${ }^{1,6}$

\section{WIC FINANCING AND ADMINISTRATIVE STRUCTURE}

The funding structure for WIC is different from the Supplemental Nutrition Assistance Program (SNAP) and other federal benefits programs in that it is a discretionary, not an entitlement, program. Entitlement programs like SNAP are available to anyone who meets the eligibility criteria. WIC has a fixed funding allocation each fiscal year; if WIC reaches the maximum budgetary allowance for a given year, they cannot add additional participants. Because of this funding structure, cost containment is essential to maximize the number of participants who can be served by WIC. ${ }^{7}$

WIC is funded at the federal level but administrated at both the federal and state level. States must meet the nutritional requirements set at the federal level, but states have some flexibility to set their own policies regarding which products are allowable. For example, states can set policy on which brands of food are allowable and set regulations about signage for product identification. WIC has traditionally been disseminated via paper vouchers, but states are in the midst of transitioning to electronic benefit transfer (EBT), or debitcard-like benefits. All states must be transitioned to EBT by the end of 2020.

\section{BEHAVIORAL ECONOMICS}

Richard and Sindelar applied behavioral economics to suggest policies for SNAP, but behavioral economics strategies have not been widely applied to WIC. ${ }^{8}$ By and large, research has explored how behavioral economics strategies in the retail food environment can encourage healthy food choice. For example, a number of marketing, product placement, and other factors can influence buyers' decision making., 9,10 Marketplace "cues," such as appealing packaging or attractive displays, may increase the likelihood of purchase. ${ }^{8}$ For WIC purchases such as whole grains, cereals, and peanut butter, cues are required to mark the eligibility of the items. For fruits and vegetables, there is often no such marking of items, because all fruits and vegetables (except prepared fruits and vegetables) are eligible for purchase.

The behavioral economics concept of "decision fatigue" can also contribute to underutilization of WIC benefits and participant attrition. Decision fatigue refers to the point at which a person becomes saturated with numerous or complicated decision-making processes and may not make the rational economic choice. ${ }^{11}$ If the process of selecting WIC-eligible items is too cumbersome, the mental "cost" of making the decision may not be worth the economic benefits. ${ }^{11}$ Decision fatigue may also affect the ability of WIC participants to select the correct WIC-eligible item, which may affect the shopping experience by causing slowdowns and potential embarrassment during checkout. For example, embarrassment during checkout may occur if a WIC participant identifies an item as WIC eligible but is unable to

\section{RESEARCH SNAPSHOT}

Research Question: What is the retail experience of WIC participants and what are ways in which it may be improved?

Key Findings: In this qualitative study, semistructured interviews and focus groups were conducted with 55 WIC participants in Texas, California, North Carolina, Oregon, and Illinois about their retail experiences. Main themes included challenges identifying WIC-allowed foods and perceived stigma during the checkout process. Better signage and training for checkout staff were identified as two ways to improve the retail experience.

purchase it at checkout, or if there are challenges in processing WIC benefits at the register.

Another concept, bounded rationality, suggests that people are not fully rational decision makers and are limited in their rational decision making by thinking capacity, available information, and time to make decisions. ${ }^{12}$ Instead, often people reply on heuristic shortcuts in decision making. ${ }^{11}$ Heuristic shortcuts are cognitive simplifications that ease decision making. ${ }^{13}$ Bounded rationality may have implications for the WIC shopping experience; when decision fatigue increases, bounded rationality may be reduced because people rely on shortcuts to make decisions.

Finally-distinct from behavioral economics but relevant to WIC participants' retail experiences-the stigma of using WIC benefits may act as a barrier to choosing healthy, low-cost options while also increasing the risk of program dissatisfaction or underutilization. Stigma is commonly experienced among federal program assistance participants, particularly in retail settings where the participant's status as a recipient of government assistance is revealed to employees doing checkout and sometimes other customers. ${ }^{14,15}$

To date, very little research has examined WIC participants' in-store experiences, and no study has applied concepts from behavioral economics to explain how aspects of the retail experience might lead to program attrition or discourage full redemption of WIC benefits. Given the gaps in research, this study asked the following questions: (1) What factors contribute to satisfaction with the retail experience among WIC recipients? (2) What is the acceptability of current item restrictions among WIC participants? These questions were answered by conducting focus groups and interviews with WIC participants.

\section{METHODS}

Focus groups and in-depth, semistructured, qualitative interviews were conducted with WIC recipients in four states (Oregon, Texas, North Carolina, and Illinois) from Fall 2014 to Spring 2016. These states were selected because they varied in WIC program administration and policies related to allowable items, use of restrictions like Least Expensive Brand (LEB) for cost containment, stage in electronic benefit transfer transition and signage requirements. Differences between states in the study are illustrated in Table 1. The LEB restriction requires recipients to select the least expensive brand within an item category, but in states without LEB restrictions, recipients can choose from a number of brands 
Table 1. Differences in WIC implementation by state

\begin{tabular}{|c|c|c|c|c|}
\hline$\underline{\text { State }}$ & $\begin{array}{l}\text { Mode of } \\
\text { administration } \\
\text { at time of data } \\
\text { collection }\end{array}$ & $\begin{array}{l}\text { Use of least expensive } \\
\text { brand for cost } \\
\text { containment }\end{array}$ & $\begin{array}{l}\text { Average value of } \\
\text { monthly WIC benefit per } \\
\text { participant at time of } \\
\text { data collection }(2015)^{16}\end{array}$ & Signage restrictions $^{12}$ \\
\hline Illinois & Paper voucher & $\begin{array}{l}\text { Yes, within } 4 \text { food } \\
\text { categories }\end{array}$ & $\$ 48.44$ & $\begin{array}{l}\text { Not provided, stores may } \\
\text { provide own }\end{array}$ \\
\hline North Carolina & Paper voucher & $\begin{array}{l}\text { Yes, within } 3 \text { food } \\
\text { categories }\end{array}$ & $\$ 42.84$ & $\begin{array}{l}\text { Not provided, stores may } \\
\text { provide own }\end{array}$ \\
\hline Oregon & Paper voucher & No & $\$ 37.48$ & $\begin{array}{l}\text { Provided by state } \\
\text { agency, required }\end{array}$ \\
\hline Texas & $\begin{array}{l}\text { Electronic } \\
\text { Benefits } \\
\text { Transfer }\end{array}$ & $\begin{array}{l}\text { Yes, within } 8 \text { food } \\
\text { categories }\end{array}$ & $\$ 29.81$ & $\begin{array}{l}\text { Provided by state } \\
\text { agency, required }\end{array}$ \\
\hline
\end{tabular}

${ }^{a}$ WIC $=$ Special Supplemental Nutrition Program for Women, Infants, and Children.

that meet the WIC nutritional requirements. All states prohibit the purchase of organic foods with WIC benefits, due to the higher cost of organic compared with conventional products, except for fruits and vegetables. The variation in state WIC policies allowed us to ascertain whether opportunities and challenges related to WIC participant experiences were specific to a certain state or were evident across state contexts.

The research team recruited participants directly through WIC state or local agencies using flyers that were distributed by WIC staff as part of a study by the Duke-University of North Carolina Center for Behavioral Economics and Healthy Food Choice Research (BECR). ${ }^{17}$ The BECR Center was funded by grant 59-5000-4-0062 from the US Department of Agriculture (USDA). The Duke Institutional Review Board approved the study protocol.

The same questions were used across two different qualitative approaches: semistructured interviews with individual participants $(n=28)$ and four focus groups $(n=27)$, lasting 45 to 60 minutes, using a semistructured guide. The guide was developed in collaboration with staff of the USDA's Economic Research Service and Food and Nutrition Service and BECR researchers. Sample questions included: "How long does it take to figure out what foods you can buy with your WIC vouchers?" and "Are you ever confused or do you ever make mistakes about what you can buy with WIC? Then what happens?" The guide is included in Figure 1 (available at www.jandonline.org). Focus group participants received a $\$ 20$ incentive and interview respondents received \$30. Participants were WIC recipients (or had children who were WIC recipients, because guardians of WIC recipients are responsible for retail purchases), were at least 18 years of age, and were involved with household food purchasing. There were no other inclusion or exclusion criteria.

All interviews and focus groups were audio recorded with permission. Audio files were transcribed verbatim, and transcriptions were stored on a password-protected database. A team of researchers and research assistants analyzed the transcripts using Dedoose qualitative analysis software (version 4.7, SocioCultural Research Consultants). Transcripts were coded using a codebook based on themes previously identified by the literature on behavioral economics and nutrition assistance program utilization. Themes were revised after an initial review of transcripts. To ensure interrater reliability, the research team engaged in multiple rounds of coding with checks of reliability. The first author double-coded a transcript with each coder $(\mathrm{n}=5)$, and Cohen's $\kappa$ was assessed using Dedoose's Code Application Training Test. A Cohen's $\kappa$ level of 0.75 was used as a benchmark to guide analysis of the remaining transcripts. This score was met by the first test by two coders and the second test by the other three coders. The Cohen's $\kappa$ for the first round of coding was 0.68 , and the Cohen's $\kappa$ for the second round was 0.88 . Any discrepancies in coding were resolved by team consensus.

\section{RESULTS}

Participant demographics are shown in Table 2. All participants were WIC recipients or had a partner or child who were WIC recipients and were one of the primary food shoppers for their household. Race was queried by asking recipients to check all that apply, so the race categories total to more than $100 \%$.

Five major themes were identified (Figure 2). Themes did not differ by data collection method (focus group vs interview).

\section{Theme A: Identification and Purchase of WIC-Eligible Items Sometimes Challenging}

Participants in all states reported variation among stores in the availability and utility of WIC labels in identifying allowable items. Most participants expressed frustration in the signage (or lack thereof) in many stores, and noted this may be a reason for program attrition (Figure 2, Theme A1).

Participants also noted that certain stores labeled WIC foods better than others. The challenge of shopping at a store that does not have sufficient WIC labeling was often a deterrent to shopping at that store (Figure 2, Theme A2). 
Table 2. Demographics of WIC ${ }^{a}$ recipients $(n=55,28$ interviewees and a total of 27 focus group participants in four focus groups)

\begin{tabular}{|c|c|c|c|}
\hline Characteristic & All participants & Focus group participants & Individual interview participants \\
\hline Age (mean) & $29.0(7.6)$ & $28.9(8.3)$ & $29.1(7.0)$ \\
\hline \multicolumn{4}{|l|}{ Gender } \\
\hline Female & $53(96.3)$ & $26(96.3)$ & $27(96.4)$ \\
\hline Male & $2(3.7)$ & $1(3.7)$ & $1(3.6)$ \\
\hline \multicolumn{4}{|l|}{ Race } \\
\hline Black or African American & $24(43.6)$ & $4(14.8)$ & $20(71.4)$ \\
\hline White & $19(34.4)$ & $12(44.4)$ & $7(25.0)$ \\
\hline Asian or Pacific Islander & $2(3.6)$ & $1(3.7)$ & $1(3.6)$ \\
\hline Native American or Alaska Native & $1(1.8)$ & $1(3.7)$ & $0(0.00)$ \\
\hline \multicolumn{4}{|l|}{ Ethnicity } \\
\hline Hispanic & $22(40.0)$ & $17(63.0)$ & $5(17.9)$ \\
\hline Non-Hispanic & $33(60.0)$ & $10(37.0)$ & $23(82.1)$ \\
\hline \multicolumn{4}{|l|}{ State of residence } \\
\hline Illinois & $5(9.1)$ & $0(0.00)$ & $5(17.9)$ \\
\hline North Carolina & $27(49.1)$ & $4(14.8)$ & $23(82.1)$ \\
\hline Oregon & $6(10.9)$ & $6(22.2)$ & $0(0.00)$ \\
\hline Texas & $17(30.9)$ & $17(63.0)$ & $0(0.00)$ \\
\hline
\end{tabular}

${ }^{a}$ WIC = Special Supplemental Nutrition Program for Women, Infants, and Children.

${ }^{\mathrm{b}} \mathrm{SD}=$ standard deviation.

There appeared to be a learning curve among WIC recipients. Participants who had received WIC for multiple years expressed higher levels of comfort with identifying WIC products than newer participants. This learning curve was reported in tandem with improvements to WIC signage, which seasoned participants had noticed improving over time (Figure 2, Subtheme A3).

Most participants reported that the information they received from the WIC office was helpful in identifying eligible items in store and in having a smooth checkout process. However, participants also had challenging experiences in retail environments when the information from the WIC office was not consistent with the in-store experience (Figure 2, Subtheme A4). No WIC client mentioned feeling stigmatized due to the presence of labels marking WICeligible foods or because of the existence of store sections devoted entirely to WIC-allowable foods (Theme D).

\section{Theme B: Stigma in the Retail Environment}

Although a small subset of participants reported only minimal stigma, most participants reported feeling stigmatized by store employees and customers when using WIC. This stigma usually happened during checkout. Participants described the frequent delays they endured while using WIC benefits. These delays often caused other customers to become frustrated (Figure 2, Subtheme B1).

Participants also noted that stigma during checkout sometimes resulted in underutilization of their WIC benefits due to pressure to finish their transactions quickly to not upset other customers (Figure 2, Subtheme B1).

Challenges during checkout often stem from the need to separate WIC items and ring up vouchers individually. Recipients in states that had not yet transitioned to EBT thought a debit card would help reduce stigma. Focus group participants from Texas, which had implemented EBT, noted how much longer use of paper benefits took compared with EBT (Figure 2, Subtheme B2). Participants had several innovative ideas to reduce stigma, such as allowing self-checkout for WIC items, having a register specifically for WIC customers, and having WIC and SNAP on the same card to streamline payment.

\section{Theme C: Benefits and Challenges of Using the CVVs for Fruits and Vegetables}

There was consensus among participants that WIC helped families afford healthier foods, particularly fruits and vegetables (Figure 2, Subtheme C1). Despite general satisfaction with the CVVs, several participants expressed difficulty in fully redeeming their benefits. CVV is the only benefit within the WIC package that has a cash, rather than a quantity, value. Because in some of the states the CVVs had to be spent all at once, participants often struggled to maximize the value of their vouchers. Even in Texas, which had recently implemented a split tender policy that allowed participants to use multiple methods of payment for items, participants expressed difficulties (Figure 2, 


\begin{tabular}{|c|c|}
\hline Themes and Subthemes & Demonstrative Quotes \\
\hline \multicolumn{2}{|c|}{ A. Identification and purchase of WIC-eligible items sometimes challenging } \\
\hline $\begin{array}{l}\text { Subtheme A1: Lack of signage is } \\
\text { frustrating to participants. }\end{array}$ & $\begin{array}{l}\text { "They recently changed the milk from } 2 \% \text { to } 1 \% \text { or low-fat and most stores that I went } \\
\text { to still had the } 2 \% \text { ones labeled. So when I take it out they are like, 'No, you can't get } \\
\text { that' and I'm like, the labels are all on } 2 \% \text {. I don't get it." (Oregon focus group) } \\
\text { "Ilt is hard to shop with WIC] because the grocery stores have things that say they're } \\
\text { WIC, but they don't go through as WIC items [at the register]. When they slide it, } \\
\text { they're not WIC items. So, it's confusing. That would be a reason for people not to } \\
\text { continue on WIC. It's frustrating." (North Carolina interview) }\end{array}$ \\
\hline $\begin{array}{l}\text { Subtheme A2: Signage and } \\
\text { purchase process varies by } \\
\text { retailer and can influence where } \\
\text { WIC foods are purchased by } \\
\text { participants. }\end{array}$ & $\begin{array}{l}\text { "It was a clerk who came in and did what she had to do and helped process it. That was } \\
\text { at [store 1]. When I got to [store 2], which is where I like to go now to get my WIC, } \\
\text { even though there may be a price difference, they seem to know what they're doing." } \\
\text { (Illinois interview) }\end{array}$ \\
\hline $\begin{array}{l}\text { Subtheme A3: Participants become } \\
\text { more comfortable with item } \\
\text { identification the longer they } \\
\text { participate in the program. }\end{array}$ & $\begin{array}{l}\text { "I've been on the program since-I have a 12-year-old, an 8-year-old, a 2-year-old, and a } \\
\text { 1-year-old. Once you've been on WIC you know what to get." (Texas focus group) } \\
\text { "A lot of the grocery stores have WIC items already labeled ... and that was one of the } \\
\text { problems early on, like 2003, that they didn't have the stuff labeled on the shelves of } \\
\text { what was WIC. But now after that, they-you can just go in and clearly spot the stuff } \\
\text { that's for WIC." (North Carolina interview) }\end{array}$ \\
\hline $\begin{array}{l}\text { Subtheme A4: WIC education can } \\
\text { be helpful in identifying and } \\
\text { purchasing eligible items, but is } \\
\text { sometimes perceived as } \\
\text { inconsistent with retail } \\
\text { information. }\end{array}$ & $\begin{array}{l}\text { "At the [WIC] office they trained me well. They said, 'Do WIC first. This is the slot to put it } \\
\text { in and tell the cashier.' And I haven't had problems." (Texas focus group) } \\
\text { "Now, certain things that they have that they say is accepted ... while have the little } \\
\text { brochure that shows that it's accepted, like [grocery store A] was where I usually go, } \\
\text { and they give me a hard time about [product selection] ... they're not on the same } \\
\text { accord with what the brochure there says." (North Carolina interview) }\end{array}$ \\
\hline \multicolumn{2}{|l|}{ B. Stigma in the retail environment } \\
\hline $\begin{array}{l}\text { Subtheme B1: Stigma is most } \\
\text { commonly experienced during } \\
\text { checkout. }\end{array}$ & $\begin{array}{l}\text { "I would just say the lines are hard to take. I've [met] people on line that you can tell are } \\
\text { irritated with me or you can tell they are like, 'Oh, God, here you go' and I have to do } \\
\text { five WIC vouchers [laughs]." (Oregon focus group) } \\
\text { "Oh, and say you get it wrong. If you get the bread or the milk wrong ... now everybody } \\
\text { [in the line] is pissed off already because they have to process three checks, but then } \\
\text { they say, 'Well, do you want this?' Sometimes you'll end up telling them, 'No, just } \\
\text { forget it. I can't get this.' Just because of the pressure." (North Carolina interview) }\end{array}$ \\
\hline $\begin{array}{l}\text { Subtheme B2: Electronic benefit } \\
\text { transfer may reduce stigma at } \\
\text { checkout and improve retail } \\
\text { experience. }\end{array}$ & $\begin{array}{l}\text { "With WIC, I wish it was a better way to handle it when going to the register. So, it } \\
\text { wouldn't take so long. If it was just on a card or something like food stamps was. It } \\
\text { wouldn't be so time-consuming. You wouldn't have people behind you blowing their } \\
\text { breath because you're taking forever." (North Carolina interview) } \\
\text { "The old school paper ones would take you forever to sign. You used to have to sign } \\
\text { to match the signature. They would fill in the price for each item on the paper." (Texas } \\
\text { focus group) }\end{array}$ \\
\hline \multicolumn{2}{|c|}{ C. Benefits and challenges of using the $\mathrm{CVVs}^{\mathrm{b}}$ for fruits and vegetables } \\
\hline $\begin{array}{l}\text { Subtheme } \mathrm{C} 1: \mathrm{CVVs} \text { help } \\
\text { participants access more fruits } \\
\text { and vegetables. }\end{array}$ & $\begin{array}{l}\text { "I know I am [buying more fruits and vegetables]. Because I would buy maybe a thing of } \\
\text { bananas every once in a while and just throw them on the counter and stuff. But now } \\
\text { when I get my WIC we buy all kinds of little vegetables-\$8 worth. As much as we } \\
\text { can. We get cucumbers, tomatoes, bananas, and apples." (North Carolina interview) }\end{array}$ \\
\hline
\end{tabular}

Figure 2. Themes and subthemes identified through focus groups and interviews about WIC $\mathrm{C}^{\mathrm{a}}$ participant shopping experiences. 


\begin{tabular}{|c|c|}
\hline Themes and Subthemes & Demonstrative Quotes \\
\hline $\begin{array}{l}\text { Subtheme C2: Maximizing the } \\
\text { value of CVVs can be } \\
\text { challenging. }\end{array}$ & $\begin{array}{l}\text { "So you have } \$ 8, \$ 10 \text { for fruits and vegetables. So you've got to calculate it right to a T, it } \\
\text { won't just be like, 'OK we're gonna take } \$ 8 \text { off, and then you're gonna pay the } \\
\text { balance.' It doesn't work like that. It'll knock off the last thing that you scanned, and } \\
\text { you'll have like } 14 \text { cents left. That's the only thing that I don't like about it." (Texas } \\
\text { focus group) }\end{array}$ \\
\hline \multicolumn{2}{|c|}{ D. WIC-only stores and sections increase customer satisfaction } \\
\hline $\begin{array}{l}\text { Subtheme D1: WIC-only stores } \\
\text { make shopping experience } \\
\text { easier and reduce decision } \\
\text { fatigue. }\end{array}$ & $\begin{array}{l}\text { "They have nothing but WIC stuff, all the WIC items. And they run your card and they tell } \\
\text { you, 'OK, you have this much of milk, how many do you want? You have this much of } \\
\text { whatever.' And they have it all there and they give it to you, and they have drive- } \\
\text { throughs as well ... you don't have to go around and find the stuff. And they're so } \\
\text { nice." (Texas focus group) }\end{array}$ \\
\hline $\begin{array}{l}\text { Subtheme D2: Clustering of WIC } \\
\text { items in existing retail outlets } \\
\text { helps with WIC item } \\
\text { identification. }\end{array}$ & $\begin{array}{l}\text { Participant 1: "And they're really good at labeling at [store 1]." } \\
\text { Participant 2: "Yeah. They're very good at labeling your WIC options on there." } \\
\text { Participant 1: "And they have a section for just WIC. Not everything is there, but } \\
\text { they have a good section of it." (Texas focus group) }\end{array}$ \\
\hline \multicolumn{2}{|c|}{ E. Participants understand need for WIC package restrictions, but they can create confusion in the retail environment } \\
\hline $\begin{array}{l}\text { Subtheme E1: Most WIC recipients } \\
\text { understand the need for } \\
\text { restrictions, though recipients } \\
\text { often want more choice in item } \\
\text { selection. }\end{array}$ & $\begin{array}{l}\text { "Yeah, I feel it [WIC item restriction] is fair because, you know, it's a lot of people on WIC. } \\
\text { So, you know, they have limit it to everybody. And if, you know, they give people } \\
\text { extra then the people that might really need it are going to miss out." (Illinois } \\
\text { interview) } \\
\text { "I wish I could get a different kind of milk. Right now I'm on like, skim or 1\%. Which I } \\
\text { prefer } 2 \% \text { or whole milk, but I'll take what I can get." (North Carolina interview) }\end{array}$ \\
\hline $\begin{array}{l}\text { Subtheme E2: WIC package } \\
\text { restrictions increase decision } \\
\text { fatigue and make shopping with } \\
\text { WIC more challenging when } \\
\text { options are unclear. }\end{array}$ & $\begin{array}{l}\text { "It's hard with the beans because you can accidentally get no salt added or you can } \\
\text { accidentally get them with something in them like bacon and so it frustrates me } \\
\text { because I won't pay attention. They won't honor any additives or low sodium or low } \\
\text { fat. Anything on the label that is not just [brand 8] pinto beans. So they'll be rejected } \\
\text { and sometimes the cans look so much alike, so it's easy to overlook that." (Texas focus } \\
\text { group) } \\
\text { "That [item restriction] is kind of complicated to me I think. There's certain kinds of food } \\
\text { or certain brands of food that you have to buy. I think that makes it [shopping with } \\
\text { WIC] so much harder." (North Carolina interview) }\end{array}$ \\
\hline
\end{tabular}

Figure 2. (continued) Themes and subthemes identified through focus groups and interviews about WIC participant shopping experiences.

Subtheme C2). These difficulties are likely due to a lack of awareness around the split tender policy.

\section{Theme D: WIC-Only Stores and Sections Increase Customer Satisfaction}

Only participants from Illinois and Texas had experiences with WIC-only stores and reported positive shopping experiences that highlighted the ease of identifying items and decreasing decision fatigue (Figure 2, Subtheme D1). Participants who had not been to WIC-only stores were asked what they would think of such stores. Many participants thought it might improve their shopping experience and reduce stigma, saying that WIC-only stores would be "easier" or "more convenient."
Although North Carolina participants did not have experience with WIC-only stores, they did note that some stores had informal WIC-focused sections that helped them identify WIC products (Figure 2, Subtheme D2).

\section{Theme E: Participants Understand Need for WIC Package Restrictions, But They Can Create Confusion in the Retail Environment}

Participants varied in their feelings about WIC food item restrictions. Most participants expressed satisfaction with WIC item restrictions, viewing restrictions as a matter of fairness that ensured those in need got assistance. Several participants did, however, express a desire for different items or brands to be WIC allowable (Figure 2, Subtheme E1). 
Some participants added that they usually shop for lowerpriced items with their personal funds, so buying those brands was familiar to them. A few participants dissented from the majority opinion of restrictions being acceptable, lamenting the poor quality of WIC-allowable brands, describing brands allowed by WIC as "the worst" and "pitiful."

For most participants, the most common complaint around restrictions was not quality, but that it increased decision fatigue and confusion around eligible items. This confusion sometimes resulted in participants selecting items that were ineligible for WIC, leading to difficulty and stigma at checkout. Confusion around what brands are allowable in each item category may result from participant misinformation, mislabeling of products, or changes to the items eligible for WIC purchase. Confusion may also stem from the mental accounting required to think about what size, variety, or brand is allowed under that food category (Figure 2, Subtheme E2).

\section{DISCUSSION}

This study applies key concepts of behavioral economics to how WIC participants experience benefit use in grocery retail settings. These findings suggest that customers experience challenges, such as decision fatigue and stigma, while using WIC. Participants noted that both poor labeling of WICallowable items and feelings of stigma when using WIC, particularly at the point of checkout, resulted in failure to use all benefits. However, interviews and focus groups suggest a learning curve in benefit use-as length of time on WIC increases, participants experience fewer challenges.

This study adds to the limited literature on WIC recipients' perceptions of their retail experiences. The results of this study are generally consistent with current literature reporting overall WIC customer satisfaction with and perceived healthfulness of the WIC food package since the 2009 revisions. ${ }^{4,18,19}$ This study is also consistent with previous literature that identifies the checkout process as a source of stigma. ${ }^{20-22}$

This study finds stigma associated with the checkout process specifically for WIC recipients using paper vouchers. Participants from Texas that had experience with EBT reported a smoother checkout process since EBT's implementation, and participants from other states expressed a desire for WIC to be administered electronically. WIC customers also expressed a desire for WIC-only stores (and WIC sections in stores), with some participants suggesting allowing self-checkout with WIC items, and a dedicated register for WIC purchases. WIC-only sections in stores and a WIC-specific checkout lane, however, are not allowed under current regulations to protect customers from stigma. Protection from stigma is important, but for participants in this study, the main source of stigma did not appear to originate from being identified as a WIC recipient, but rather from the lengthy checkout process that frustrated other customers. Therefore, stigma may be reduced if the checkout process were made smoother.

The incorrect labeling of WIC-allowable items does negatively affect the shopping experience. Participants were frustrated when items were incorrectly labeled, and the mislabeling may contribute to underutilization of WIC benefits. The behavioral economics concepts of bounded rationality and decision fatigue clarify how mislabeling may affect the use of benefits and program attrition.

Decision fatigue may be especially relevant for WIC shoppers, because they often must select many different food items from their WIC package in one shopping trip (eg, fruits and vegetables, whole grains, juice). Decision fatigue from improperly labeled products and multiple item categories may cause WIC participants to abandon the purchase or selection of certain WIC items. Bounded rationality also suggests that if items are poorly labeled, or if there have been changes to the WIC item eligibility that the customer is unaware of, recipients may use shortcuts such as knowledge of what items were previously eligible or what items they think should be eligible to select products.

Another behavioral economics principle, loss aversion, or a preference for avoiding a loss more than gaining something of the equivalent amount, was also visible in our study, particularly with the use of the CVV for fruits and vegetables. ${ }^{23}$ Participants lamented the inability to save money left over on the voucher if they could not spend it in one trip. The potential cognitive overload of weighing produce to an exact dollar amount that may not be exceeded may have contributed to underutilization of the CVV. As of October 2017, however, all states enabled split tender when transacting WIC benefits, allowing participants to pay the difference when a purchase exceeds the value of the CVV. ${ }^{24}$ This type of policy may help to reduce the loss aversion that participants experience. Texas was the only state in our sample that had implemented the split tender policy at the time of data collection, but focus group participants were not aware of the policy. This lack of awareness is likely because split tender was implemented shortly before data collection occurred. Given the lag from policy implementation to customer awareness, further research should explore WIC recipients' current knowledge of the split tender policy given its implementation in October 2017.

In some instances, participant or retailers' mistakes can lead to selecting items that are not WIC approved. These findings suggest that education from the WIC office can help participants identify WIC-approved items in store. The quality, type, and setting of education received from the WIC offices varies, and future efforts should continue to ensure best practices are shared nationwide. WIC shopping education is traditionally provided during visits to the WIC clinic but is often not offered at retail locations. By offering WIC shopping education in store, WIC offices can reduce the stigma that arises at checkout when participants mistakenly select items that are not allowed. Continued collaboration with local WIC offices and improved education of store cashiers and other personnel (eg, shelf stockers) may help ensure consistent and correct labeling. As noted previously, WIC-only sections of stores may also help reduce confusion around labeling and item selection. This study found that labeling and ease of WIC food identification were factors in WIC recipients deciding where to use their benefits. This finding may be useful when communicating to retailers the importance of clearly labeling WIC foods for potential revenue gains.

Participants in study sites with WIC-only stores appreciated these kinds of retailers. WIC-only stores account for 
approximately $7.7 \%$ of total WIC sales, ${ }^{25}$ and in this sample, only participants from Illinois and Texas had shopped at WIConly stores. Although WIC-only stores can help reduce the decision fatigue of identifying eligible items and stigma experienced at checkout, these stores are not always economically viable. ${ }^{26,27}$

Participants were satisfied with the CVV for fruits and vegetables, but also noted challenges in utilizing the voucher to its maximum value. Most study participants also found restrictions on allowable foods to be acceptable and helped them to eat healthier, although some participants desired more flexibility in brand selection. This study also identified brand restriction as an acceptable cost-containment measure, although allowable items must be clear to participants and not contribute to stigma.

This study has both strengths and limitations. A key strength is that to the authors' knowledge, this study is the first of its kind to explore the shopping experiences of WIC participants across different WIC state policy contexts. Themes were consistent across the different states, except the distinct experience of participants from states that had already transferred to EBT, who noted that this switch had reduced stigma at checkout. Consistent themes across states suggest that these themes may be common in other state WIC settings regardless of state-specific policies. However, additional research in other states is needed to confirm the generalizability of these findings to a national population, a limitation of this study. Another key limitation is that participants may have been hesitant to complain about a program that they think they are supposed to appreciate. Furthermore, participants who had dropped out of the WIC program were not included, and their views may have differed from those who had stayed in the program. Last, this study used a convenience sample from four states, so the findings may not be nationally representative.

\section{CONCLUSIONS}

This study provides clues as to how to change WIC program administration and retail operations to improve the WIC participant experience and address attrition. This study found that participants are generally not dissatisfied with the products themselves but have trouble identifying WICapproved items in stores. To that end, research is needed on potential ways to improve the WIC participant experience, such as the effectiveness of increased visibility of in-store signage, usage of smartphone apps to identify allowable items, WIC-only store sections and checkout lanes, and expanded authorization of WIC-only stores. In addition, instore education opportunities for participants, improved cashier and vendor training on ways to avoid stigma, and improved signage provided to vendors by state agencies may help to improve the WIC shopping experience. Because many of these suggested improvements are influenced by statelevel policies, it is integral for federal and state WIC agencies to collaborate with local WIC offices and vendors on policy development.

At the time of data collection, only one of the states in this study (Texas) had implemented EBT. Because all states should be transitioned to EBT by the end of 2020, our results suggest that stigma during checkout may be reduced nationwide. As states implement EBT, more research will be needed to further explore how EBT affects the WIC shopping experience.

During the writing of this manuscript, split tender implementation, which allows participants to pay the difference for CVV purchases, was implemented in all states. ${ }^{24}$ Ongoing education for WIC recipients on the split tender policy may increase CVV redemption. Further research should test the effectiveness, feasibility, and acceptability of these suggested strategies among WIC recipients. These behavioral economics-informed strategies can potentially reduce stigma, improve the retail experience, increase food benefit use, and increase program satisfaction and potentially retention in the WIC program.

\section{References}

1. Ogden CL, Carroll MD, Kit BK, Flegal KM. Prevalence of obesity and trends in body mass index among US children and adolescents, 1999-2010. JAMA. 2012;307(5):483-490.

2. Hales CM, Fryar CD, Carroll MD, Freedman DS, Ogden CL. Trends in obesity and severe obesity prevalence in US youth and adults by sex and age, 2007-2008 to 2015-2016. JAMA. 2018;319(16): 1723-1725.

3. Fryar CD, Carroll MD, Ogden CL. Prevalence of overweight, obesity, and extreme obesity among adults aged 20 and over: United States, 1960-1962 through 2013-2014. National Center for Health Statistics. Health E Stats. 2016 (July). https://www.cdc.gov/nchs/data/hestat/ obesity_adult_13_14/obesity_adult_13_14.pdf. Accessed April 20, 2018.

4. Schultz DJ, Byker Shanks C, Houghtaling B. The impact of the 2009 Special Supplemental Nutrition Program for Women, Infants, and Children food package revisions on participants: A systematic review. J Acad Nutr Diet. 2015;115(11):1832-1846.

5. US Department of Agriculture. National and State-Level Estimates of Special Supplemental Nutrition Program for Women, Infants, and Children (WIC) Eligibles and Program Reach, 2015. Washington, DC: United States Department of Agriculture, Food and Nutrition Services; 2018. https://fns-prod.azureedge.net/sites/default/files/ops/ WICEligibles2015-Volume1.pdf. Accessed April 20, 2018.

6. National Academies of Sciences, Engineering and M. Review of WIC Food Package: Improving Balance and Choice: Final Report. Washington, DC: National Academies Press; 2017.

7. National WIC Association. WIC Program Overview and History. https://www.nwica.org/overview-and-history. Accessed February $25,2015$.

8. Richards MR, Sindelar JL. Rewarding healthy food choices in SNAP: behavioral economic applications: rewarding healthy food choices in SNAP. Milbank Q. 2013;91(2):395-412.

9. Roberto CA, Kawachi I. Use of psychology and behavioral economics to promote healthy eating. Am J Prev Med. 2014;47(6):832-837.

10. Riis J. Opportunities and barriers for smaller portions in food service: Lessons from marketing and behavioral economics. Int J Obes (Lond). 2014;38(Suppl 1):S19-24.

11. Rice T. The behavioral economics of health and health care. Annu Rev Public Health. 2013;34:431-447.

12. Kahneman D. Maps of bounded rationality: Psychology for behavioral economics. Am Econ Rev. 2003;93:1449-1475.

13. Simon HA. Models of Bounded Rationality. Cambridge, MA: MIT Press; 1982.

14. Powell L, Amsbary J, Xin H. Stigma as a communication barrier for participation in the federal government's Women, Infants, and Children Program. Qual Res Reports Commun. 2015;16(1):75-85.

15. National WIC Association. WIC research to practice hot topic: Caseload decrease. https://www.nwica.org/blog/wic-researchto-practice-hot-topic-caseload-decrease\#.Vt3ootB0szI. 2015. Accessed March 7, 2018.

16. United States Department of Education Food and Nutrition Services. WIC Program. Average cost per participant. 2017. https://www.fns. usda.gov/sites/default/files/pd/25wifyavgfd\%24.pdf. Accessed April $18,2018$. 
17. BECR Center: About us. https://becr.sanford.duke.edu/. Accessed April 20, 2018. Accessed April 20, 2018.

18. Ritchie LD, Whaley SE, Crocker NJ. Satisfaction of California WIC participants with food package changes. J Nutr Educ Behav. 46(3 Suppl):S71-S78.

19. Chiasson MA, Findley SE, Sekhobo JP, et al. Changing WIC changes what children eat. Obesity. 2013;21(7):1423-1429.

20. Bertmann FMW, Barroso C, Ohri-Vachaspati P, Hampl JS, Sell K, Wharton CM. Women, infants, and children cash value voucher (CVV) use in Arizona: A qualitative exploration of barriers and strategies related to fruit and vegetable purchases. J Nutr Educ Behav. 2014;46(3 Suppl):S53-S58.

21. Bryant C, Lindenberger J, Brown C, et al. A social marketing approach to increasing enrollment in a public health program: A case study of the Texas WIC Program. Hum Organ. 2001;60(3):234-246.

22. Birkett D, Johnson D, Thompson JR, Oberg D. Reaching low-income families: Focus group results provide direction for a behavioral approach to WIC services. J Am Diet Assoc. 2004;104(8): 1277-1280.
23. Thorgeirsson T, Kawachi I. Behavioral economics: merging psychology and economics for lifestyle interventions. Am J Prev Med. 2013;44(2):185-189.

24. US Food and Drug Administration. WIC Policy Memorandum \#20172. State Agency Compliance with Split Tender Requirements. 2016. https://fns-prod.azureedge.net/sites/default/files/wic/WIC-PolicyMemo-2017-2.pdf. Accessed January 23, 2018.

25. Tiehen L, Frazao E. Where do WIC participants redeem their food benefits? An analysis of WIC food dollar redemption patterns by store type. Economic Information Bulletin-152. US Department of Agriculture, Economic Research Service, 2016. https://www.ers.usda. gov/webdocs/publications/44073/57246_eib152.pdf?v=0. Accessed October 30, 2018.

26. Wheeler AL, Chapman-Novakofski K. Farmers' markets: costs compared with supermarkets, use among WIC clients, and relationship to fruit and vegetable intake and related psychosocial variables. J Nutr Educ Behav. 2014;46(3 Suppl):S65-S70.

27. Neuberger Z, Greenstein R. WIC-Only Stores and Competitive Pricing in the WIC Program. Center on Budget and Policy Priorities. 2004. http://www.cbpp.org/research/wic-only-stores-and-competitivepricing-in-the-wic-program. Accessed January 16, 2017.

\section{AUTHOR INFORMATION}

C. Chauvenet is a PhD candidate, Maternal and Child Health, Royster Fellow at University of North Carolina Center for Health Promotion and Disease Prevention and University of North Carolina at Chapel Hill Gillings School of Global Public Health, Department of Maternal and Child Health, Chapel Hill. M. De Marco is a research assistant professor, Department of Nutrition, Gillings School of Global Public Health Research Fellow and project director, Center for Health Promotion \& Disease Prevention (a CDC Prevention Research Center), University of North Carolina at Chapel Hill. C. Barnes is an assistant professor, Sanford School of Public Policy and assistant professor of political science, Duke University, Durham, NC. A. S. Ammerman is director, Center for Health Promotion and Disease Prevention, Kauffman Distinguished Professor, Department of Nutrition, Gillings School of Global Public Health and School of Medicine, University of North Carolina at Chapel Hill.

Address correspondence to: Christina Chauvenet, MSc, MSPH, University of North Carolina Center for Health Promotion and Disease Prevention and University of North Carolina at Chapel Hill Gillings School of Global Public Health, Department of Maternal and Child Health, 1700 Martin Luther King Jr Boulevard, CB\# 7426, Chapel Hill NC 27599. E-mail: chauca4@live.unc.edu

\section{STATEMENT OF POTENTIAL CONFLICT OF INTEREST}

No potential conflict of interest was reported by the authors.

\section{FUNDING/SUPPORT}

This study was conducted as part of the Duke-UNC USDA Center for Behavioral Economics and Healthy Food Choice Research (BECR). The BECR Center was funded by grant 59-5000-4-0062 from the US Department of Agriculture. The views expressed are those of the authors and do not represent those of the US Department of Agriculture, its Economic Research Service or Food and Nutrition Service.

\section{ACKNOWLEDGEMENTS}

The authors thank Ruth Morgan, MPH, and Joanne Guthrie, MPH, PhD, RD, from the US Department of Agriculture (Food and Nutrition Service and Economic Research Service, respectively) for their policy expertise in reviewing this manuscript. The authors also thank Julia Cruz, MS, MD, from George Washington University, for her thorough review of the manuscript. The authors also thank Carly Bandt; Logan Kirkpatrick; Emily Rains; Jewels Rhode, MPH; and Kiera Vinson, MPP, for their assistance in data collection and coding qualitative interviews and focus groups.

\section{AUTHOR CONTRIBUTIONS}

C. Barnes, M. De Marco, and A. S. Ammerman originated the study, developed the methods and research questions and listening session and interview guides, and collected the data. C. Chauvenet and M. De Marco wrote the first draft of the manuscript with contributions from C. Barnes. All authors reviewed and commented on all drafts of the manuscript. 


$$
\begin{array}{r}
\text { Date: } \\
\text { Location: } \\
\text { \# Participants: } \\
\text { Facilitator: }
\end{array}
$$

\section{Duke-University of North Carolina US Department of Agriculture Center for Behavioral Economics \& Health Food Choice Research}

Focus Group Interview Guide for Special Supplemental Nutrition Program for Women, Infants, and Children Participants

We'd like to learn about your experiences grocery shopping for yourself and your family. We are interested in finding out how you navigate shopping using cash, Special Supplemental Nutrition Program for Women, Infants, and Children (WIC) food instruments (cash value vouchers), and Supplemental Nutrition Assistance Program (SNAP) benefits (if applicable).

1. When you shop for groceries, where do you go? (Probes: How many stores? How do you get there? How many trips in a typical month?) What is your main store, where you buy most of your groceries?

Let's talk about shopping using WIC instruments. What is it like using WIC instruments to purchase food?

2.

a. Do you redeem WIC vouchers at the store you usually shop at? If you redeem them at other stores, how do you decide which store or stores to go to for your WIC foods? For example, are there some stores that have better WIC food selection, or where WIC items are better labeled? (Probes: location, transportation)

b. Do you ever buy your WIC foods at corner or convenience stores? What makes you choose to shop there?

c. How long does it take to figure out what foods you can buy with your WIC vouchers? Is there information from the clinic or in the store that you can use to tell you what you can buy with WIC? Is it helpful? Are you ever confused or do you ever make mistakes about what you can buy with WIC? Then what happens?

d. Often you can choose different products with your WIC voucher, like different brands of cereal or different package sizes-a bigger box or a smaller box. How do you decide which product to buy? Do you consider the price of the items you choose when using your WIC vouchers, for example cereal? How do you choose which cereal to purchase?

e. Are there some products, like juice, cheese, or cereal, that you sometimes buy with WIC and sometimes buy with your own money or SNAP? When you buy with WIC, do you buy a different product than you buy with your own money or SNAP?

f. For some product categories, like cheese, you can only use WIC to buy some items, not all of them. Sometimes this is because of price. Do you feel that WIC clients should be restricted to buying only lower-cost items (like the lower-cost cheese)? Why or why not?

g. If you don't already choose the cheapest item, such as the lowest-priced milk/eggs/cheese, what would make you more likely to do that?

h. Do you usually purchase all the items on your WIC voucher? If not, why not?

i. Are there certain WIC products that you never buy?

3. Do you use grocery store loyalty cards? Are they helpful in budgeting? Can you use them with WIC? If you can, do you usually use them with WIC?

(Time permitting) The next questions are about healthy eating and SNAP.

4. What are the challenges for trying to buy healthy foods when your family is on SNAP and/or WIC?

5. What are some ways that a grocery store could make buying healthy foods more convenient?

6. What are some ways that healthy foods could be made more convenient to prepare at home?

7. Do you feel like you have the knowledge you need to choose and prepare healthy foods on a tight budget?

a. What information do you wish you knew?

8. Can you keep and prepare foods the way you want to when you're at home?

(continued on next page)

Figure 1. Duke-University of North Carolina US Department of Agriculture Center for Behavioral Economics \& Health Food Choice Research: Focus Group Interview Guide for Special Supplemental Nutrition Program for Women, Infants, and Children Participants. 
9. How does SNAP and/or WIC participation affect your purchases of fresh fruits and vegetables?

a. Are you able to find the varieties you want at your local store?

10. How do you choose which beverages to buy or have at home?

a. How do you choose between sugary drinks and other drinks such as water, milk, and $100 \%$ fruit juice?

11. How do food and cooking fit in with the other demands on your time?

12. How does SNAP and/or WIC participation affect your purchases of whole grain foods (bread, pasta, buns, cereal)?

a. Are you able to find the varieties you want at your local store?

13. How much do you think about the health of the food that you purchase?

14. Is the food you can purchase as healthy as you want it to be?

15. How do you manage food in your household to minimize food spoiling?

16. Do you shop at farmers' markets?

a. Why or why not?

b. What do you use to make purchases at farmers' markets? (SNAP/EBT [electronic balance transfer], WIC Farmers' Market coupons, cash)

c. What do you purchase at farmers' markets?

17. When you shop for food, do you use a shopping list?

18. Do you plan your meals in advance?

19. What do you think would help you to eat healthier meals?

20. If you were going to suggest changes to improve the WIC program, what would you recommend?

21. How did you find you that you were eligible for WIC?

22. If you were going to suggest changes to improve the SNAP program, what would you recommend?

23. Is there anything else you think I should know?

1. Now, if you have SNAP benefits, what is it like using those to buy food?

2. (For SNAP recipients) How long do your SNAP benefits last during a typical month?

a. How much of your SNAP benefits do you spend in the first week? After that, how do you spend the benefits?

b. How do your purchases of perishable foods, like fresh fruits, vegetables, milk, and meats, vary over the course of a month?

c. Are your meals different at the beginning, middle, and end of the month? How?

3. What about SNAP benefits might keep people from making healthy food choices? (Probes: prices, availability)

a. Have you experienced these barriers personally? If so, what did you do to overcome them?

4. In your opinion, what are some ways that SNAP makes healthy foods easier to get?

a. Are there particular programs in SNAP that have helped make healthy foods more accessible? Did you take advantage of these programs?

Figure 1. (continued) Duke-University of North Carolina US Department of Agriculture Center for Behavioral Economics \& Health Food Choice Research: Focus Group Interview Guide for Special Supplemental Nutrition Program for Women, Infants, and Children Participants. 